\title{
Coexistence of African lions, livestock, and people in a landscape with variable human land use and seasonal movements
}

\author{
Authors: Paul Schuette, Scott Creel, and David \\ Christianson
}

NOTICE: this is the author's version of a work that was accepted for publication in Biological Conservation. Changes resulting from the publishing process, such as peer review, editing, corrections, structural formatting, and other quality control mechanisms may not be reflected in this document. Changes may have been made to this work since it was submitted for publication. A definitive version was subsequently published in Biological Conservation, [VOL\# 157, (January 2013)]

DOI\# 10.1016/j.biocon.2012.09.011

Schuette P, Creel S \& Christianson D 2013. Coexistence of African lions, livestock, and people in a landscape with variable human land use and seasonal movements. Biological Conservation 157: 148-154.

Made available through Montana State University's ScholarWorks scholarworks. montana.edu 


\title{
Coexistence of African lions, livestock, and people in a landscape with variable human land use and seasonal movements
}

\author{
Paul Schuette ${ }^{\mathrm{a}, *}$, Scott Creel $^{\mathrm{a}}$, David Christianson ${ }^{\mathrm{b}}$ \\ ${ }^{a}$ Department of Ecology, 310 Lewis Hall, Montana State University, Bozeman, MT 59717, USA \\ ${ }^{\mathrm{b}}$ School of Natural Resources and the Environment, University of Arizona, Biological Sciences East, Tuscon, AZ 85721, USA
}

\begin{abstract}
Apex carnivores around the world have experienced rapid population declines and local extirpation due to anthropogenic pressures, and they are increasingly restricted to government-protected areas (GPAs). Though GPAs are critical for carnivore conservation, mixed-use landscapes may be crucial for sustaining viable populations. Few studies, particularly in Africa, have examined joint use of a landscape by people and conflictprone carnivores, such as the African lion (Panthera leo), in a situation where conflict is low. In southern Kenya, we studied a lion population in an unfenced rangeland occupied by the Maasai people and their livestock. The Maasai shift their settlements and grazing areas seasonally across a permanent river, a practice we hypothesized might promote coexistence. We radio-collared lions $(n=6)$ to determine density and document spatial patterns in response to seasonal movements of people in a Conservation Area and buffer zone $\left(250 \mathrm{~km}^{2}\right)$. Despite high livestock density, lion density was compara-ble to many GPAs $(0.136$ individuals $/ \mathrm{km}^{2}$ ). Lion spatial distribution and habitat selection shifted in rela-tion to seasonal movements of people and livestock. Conflict was low, likely because lions increased their use of the Conservation Area and dense habitats when people were nearby. Lion responses to human movements reduced access to permanent water, but not prey. A land use system based on temporary set-tlements and grazing areas allowed lions to co-occur with people and livestock at high density. These results suggest a general strategy for the conservation of apex carnivores outside of GPAs, focusing on areas that exhibit spatiotemporal variation in human land use.
\end{abstract}

\section{Introduction}

In the past century, carnivore populations have experienced drastic, global reductions due to increasing human population densities, habitat loss and fragmentation, reduced prey availability, and elevated rates of conflict (Gittleman et al., 2001). These declines are most severe in large species, which require large areas with intact prey communities, and are prone to killing livestock (Woodroffe, 2000). As a result, large carnivores are usually among the first species to disappear from landscapes, often with strong cascading effects on ecosystem structure and function (Estes et al., 2011).

Most large African carnivore species, including the African wild dog (Lycaon pictus), cheetah (Acinonyx jubatus) and African lion (Panthera leo) have declined markedly in their geographic range and population sizes. The geographic range of lions is now $22 \%$ of their historic range (Bauer et al., 2008). Many regional lion populations have been locally extirpated and others are increasingly isolated within national parks and other government-protected areas
(GPAs), which are not immune to anthropogenic pressures (Woodroffe and Ginsberg, 1998). As a result, the continent-wide lion estimate is now less than 25,000 individuals, compared to more than 100,000 individuals only 40 years ago (Bauer et al., 2008). Continent-wide geographic and numeric declines of $~ 75 \%$ in roughly 10 generations are cause for serious, immediate conservation concern.

In East Africa, extant lion populations have been exposed to a rapidly changing human landscape. For thousands of years, many East African rangelands were inhabited by low-density, nomadic pastoralist communities who moved with their herds seasonally, following the rains to secure forage for their livestock (Marshall, 1990). Recent government land policies and rapid population growth have discouraged pastoralism and encouraged permanent human settlements, land privatization, and crop production (Homewood et al., 2009). These land use changes have converted, fragmented, and restricted access to important habitats for lions (Ogutu et al., 2005), including dense cover and riparian areas, which are important for stalking predators such as lions (Mosser et al., 2009; Spong, 2002). In addition, many agro-pastoralist landscapes have livestock densities and grazing intensities that can competitively displace native ungulate species (Groom and Harris, 
2010). This process has contributed to large, ongoing decreases in ungulate densities across Africa (Craigie et al., 2010), and thus, declines in large carnivores that specialize on ungulates. The detrimental impacts of land use change and decreased prey availability are well-documented in many areas where humancarnivore conflict rates are high (Hazzah et al., 2009; Patterson et al., 2004).

In Kenya, lions are thought to have decreased from approximately 2750 individuals to 2000 in 10 years, a decline of nearly 30\% (Kenya's National Large Carnivore Task Force, 2010). Many of the remaining lion populations lie within southern Kenya's GPAs (Kenya's National Large Carnivore Task Force, 2010), including the Maasai Mara National Reserve, where lion densities are perhaps the highest in Africa (Ogutu and Dublin, 2002). Even in this lion hotspot, anthropogenic mortality is common along the reserve boundary, where human-wildlife conflict is high as crop production has become more common and livestock populations have increased (Ogutu et al., 2005). In these circumstances, GPAs may serve as ecological sources and neighboring community lands as ecological sinks (Woodroffe and Ginsberg, 1998). Similar source-sink dynamics exist for lions in Zambia's South Luangwa National Park and adjacent Game Management Areas, where lion mortality is unsustainably high (Becker, in press).

Despite these patterns, unprotected arid rangelands in Kenya are estimated to support $65 \%$ of the country's lion population (Chardonnet, 2002). Rangelands that occur in the southern Rift Valley of Kenya retain conditions that have the potential to support a viable lion population outside of any central-government protection. This region is inhabited by the Maasai people, who retain many of their traditions, including seasonal movements with their herds to secure grazing forage. This land use system, coupled with low human population density, has likely contributed to locally high livestock and native ungulate densities occurring on the same landscape (Schuette, 2012). Apex predators, including lion, occur in the region with little reported conflict over the past decade (Kenya Wildlife Service, personal communication). We are unaware of any census data on the southern Rift Valley lion population or the severity of human-lion conflict beyond this time frame. However, historical evidence suggests that the Maasai hunted lions only in response to specific livestock depredation events and during traditional lion hunts by young Maasai warriors as a cultural rite of passage (Tarayia, 2004). Though traditional lion hunts are now illegal in Kenya, we suspect that many of the conditions that have allowed the Maasai to co-occur with abundant wildlife, including lions, for centuries (Marshall, 1990), may still hold true in the southern Rift Valley.

From 2008 to 2011, we studied the lion population on Olkiramatian and Shompole Maasai Group Ranches in the southern Rift Valley of Kenya with two objectives. First, we radio-collared $\geqslant 1$ individual from every resident pride and male coalition to determine absolute density by counting recognized individuals. Second, we quantified changes in lion space use in response to seasonal movements of the Olkiramatian and Shompole community from the east side of a permanent river to the west side of the river, which includes a community-managed Conservation Area (CA). The CA, designated in 2001, allows the community to implement wildlife and land management policies at the local (rather than central government) level and collect fees from tourists with revenues shared by the community (Tarayia, 2004). Lastly, we collected conflict reports in collaboration with local Maasai natural resource assessors to determine the extent of human-carnivore conflicts in the area.

We tested three hypotheses regarding potential lion responses to seasonal movements of people to areas west of the river during the dry season. Specifically, we hypothesized that (1) lions would maintain a threshold distance from occupied human settlements to avoid direct contact and consequent persecution, (2) lions would increase their use of the CA and dense habitats (which provide protective cover) compared to times when people only inhabited areas east of the river, a pattern that would result in low rates of conflict, and (3) a spatial shift by lions would limit their access to areas near the permanent river and decrease access to prey (thus carrying costs).

\section{Materials and methods}

\subsection{Study area}

This study was conducted in the southern Rift Valley of Kenya on the Olkiramatian and Shompole Maasai Group Ranches from January 2008 to February 2011. This semi-arid rangeland consists primarily of open and closed bushlands and Acacia woodlands, and patches of open grassland. The area receives low annual rainfall (400-600 mm/year), primarily from March-May and November-December. Rainfall was well below average $(327 \mathrm{~mm})$ in 2009. The permanent Ewaso Nyiro River bisects the study area, flowing from north to south into the Shompole swamp and then into Lake Natron in northern Tanzania (Fig. 1).

A relatively low density Maasai community ( $\sim 10$ people $\left./ \mathrm{km}^{2}\right)$ inhabits Olkiramatian and Shompole. This community subsists primarily on their livestock, which occur at moderate to high densities (sheep/goats: $59.1 \pm 17.0$ individuals $/ \mathrm{km}^{2}$, cattle: $15.8 \pm 5.7$ individuals $/ \mathrm{km}^{2}$ ) (Schuette, 2012). Despite increasing land subdivision and farmland production on surrounding rangelands (Homewood et al., 2009), this region is unfenced in all directions. With the exception of the Rift Valley escarpment directly to the east, Olkiramatian and Shompole are part of a contiguous trans-boundary arid rangeland ecosystem encompassing $>8000 \mathrm{~km}^{2}$ that extends across southern Kenya and northern Tanzania. Locally, the Olkiramatian and Shompole landscape is partitioned into four land uses (Fig. 1), including (from west to east) (1) a community Conservation Area (CA) that is normally unoccupied but can be used as a daytime livestock grazing refuge under drought conditions, (2) a buffer area that is occupied seasonally by Maasai and grazed by livestock during the dry season ( September-March), (3) a grazing area that is seasonally grazed in the wet season ( $\sim$ March-September) with no settlements, and a (4) permanent settlement area that people and livestock occupy more consistently throughout the year. Here, we focus on the CA and Buffer land use types on the west side of the river, which span an area of $250 \mathrm{~km}^{2}$. Though lions do occur on the east side of the river in the grazing and permanent settlement areas, their estimated occupancy levels were low compared to the west side of the river (Schuette et al., in press). Decisions on when and where to settle and graze their livestock are made by a committee of Maasai community members. Livestock herds are always accompanied by one or more herdsman and a guard dog during daytime hours (0600-1800). At night, livestock are kept within a thornbrush corral positioned at the center of each Maasai settlement to protect their herds from predation.

The site holds diverse large herbivore and carnivore communities. Densities of the five most common native ungulates [zebra (Equus quagga), Grant's gazelle (Nanger granti), wildebeest (Connochaetes taurinus), impala (Aepyceros melampus), and Maasai giraffe (Giraffa camelopardalis tippelskirchi)] are comparable to many GPA populations, despite being outnumbered $3-1$ by livestock $\left(74.9 \pm 22.7\right.$ livestock $/ \mathrm{km}^{2}, 28.2 \pm 9.2$ native ungulates $\left./ \mathrm{km}^{2}\right)($ Schuette, 2012). The site holds $\geqslant 21$ carnivore species, including all apex predators: lion ( $P$. leo), spotted hyena (Crocuta crocuta), leopard (Panthera pardus), cheetah (A. jubatus), and African wild $\operatorname{dog}(L$. pictus) (Schuette et al., in press). 

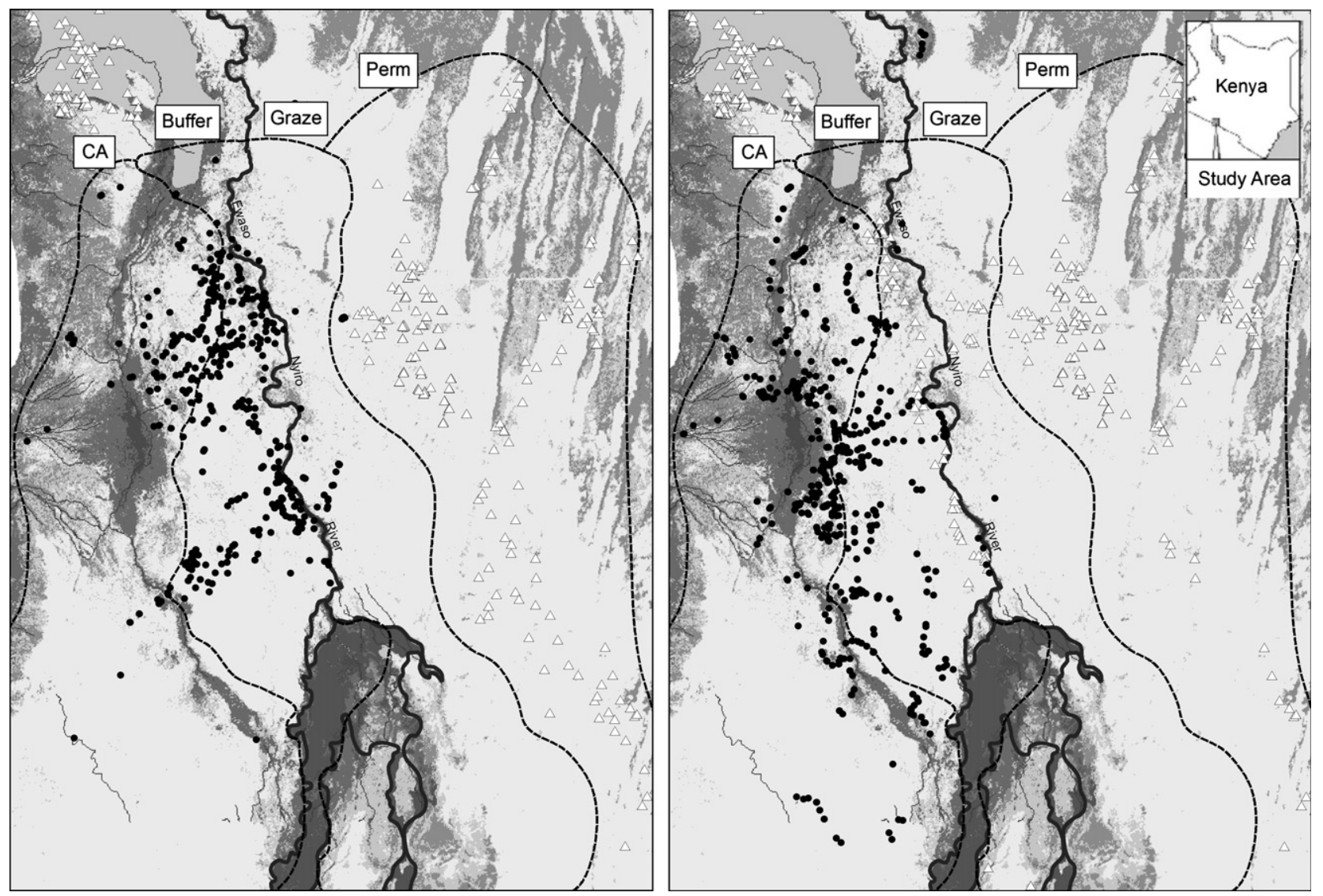

Fig. 1. Lion locations (black circles) relative to human settlements (white triangles). The figure at left shows lion locations when people were primarily settled east of the permanent river. The figure at right shows lions locations when people were settled west of the permanent Ewaso Nyiro River. Dark shading represents a gradient of dense vegetation from open (light color) to closed (dark). The Ewaso Nyiro is the only permanent river: all other watercourses were seasonally dry.

\subsection{Sampling design}

We used radiotelemetry to monitor lions within the Olkiramatian and Shompole Group Ranches to determine local lion population density and space use patterns. We fixed Telonics (Mesa, AZ, USA) MOD-400 VHF transmitters with butyl belting collars to 12 adult female lions per resident pride and 1 collar per resident male coalition. In total, we deployed six radio collars among three resident prides and two male coalitions. One additional resident pride and two male coalitions occurred in the area but were not collared because they were too shy to approach. All lions were immobilized using a medetomidine/ketamine combination and reversed with atipamezole (West et al., 2007).

We followed radio-collared groups in a $4 \mathrm{WD}$ vehicle using a VHF-antenna (Telonics) and handheld receiver (Communications Specialists, Orange, CA, USA). Lion follows were conducted primarily during the night and early morning hours (1800-0859 h) to document group size and composition and space use patterns in periods when lions were most active. All lions in each pride and coalition were uniquely identified by photographing unique whisker patterns, ear notches, and facial scars (Pennycuick and Rudnai, 1970). We used red-filtered spotlights and dimmed headlights and followed at a distance that minimized disturbance to lions and potential prey animals, usually $\geqslant 100 \mathrm{~m}$. Lions rarely reacted to the vehicle, and we stopped immediately if we detected any reaction. (Note that any effect of our presence would be expected to affect all of the data, and thus would not explain the effects of land use that we observed.) We attempted to locate and follow each radio-collared group at least once per week. During each group follow, we recorded a GPS location of the radio-collared group at
5-10 min intervals when lions were actively moving, every 15 min when stationary, at every transition from stationary to active, and when specific hunting behaviors (not discussed here) occurred. On each occasion, we recorded only one GPS location per group, so that the group (not the individual) is the unit for spatial analysis. We periodically located radio-collared groups during the daytime hours (0900-1759 h) to document daytime resting locations. All daytime locations were spaced a minimum of $24 \mathrm{~h}$ apart to ensure we collected only one daytime location per group per day.

At each GPS fix, we recorded the habitat type, classified as open (open grassland or low-density bushland/woodland) or closed (high density bushland/woodland and riparian areas) and weather conditions (e.g. temperature, wind speed, cloud cover). We used geographic information system software (ArcGIS 9.2) to categorize each lion location as either in the CA or buffer area. We also determined the distance (meters) between each lion location and the permanent river, and the distance to the nearest active human settlement, which were mapped monthly (an appropriate scale). As indicated in Fig. 1, only a portion of settlements were occupied by people and livestock throughout the year, and thus, it was important in our analysis to indicate which settlements were actively used each month. We determined the potential influence of local prey (combined zebra, Grant's gazelle, wildebeest, impala, giraffe) on lion spatial patterns by relating ungulate densities to each lion location. We estimated ungulate densities with systematic ground counts along line transects. Every 6 weeks, a team of three observers surveyed by vehicle sixteen transects ( 8 east and 8 west of the river) spaced at $4-\mathrm{km}$ intervals. We recorded the distance (meters) and bearing of all native and domestic ungulates 
encountered, and estimated densities using distance sampling (Buckland, 2001; Chandler, 2012; Schuette, 2012). We used only the subset of lion locations (55\%) for which we had a local prey density estimate from recent ( $\leqslant 3$ weeks) distance sampling on a nearby $(\leqslant 2 \mathrm{~km})$ line-transect.

A team of eight local Maasai Resource Assessors, which were employed by the South Rift Association of Landowners (SORALO), a Maasai non-profit organization, collected carnivore conflict reports. These reports were collected during monthly livelihood surveys of Olkiramatian and Shompole residents to monitor socio-economic and ecological conditions that influence Maasai livelihoods. As part of these surveys, Resource Assessors recorded all incidents of human-carnivore conflict, which were defined as an attack by a carnivore on their cattle, sheep, or goats that lead to an injury or death. In addition, each Resource Assessor was stationed within their home region, which allowed them to also record conflict reports opportunistically. We examined conflict reports that accumulated over 3 years (2008-2010) as an index of human-carnivore conflict in the area.

\subsection{Statistical analysis}

We quantified lion density from a count of all uniquely identified individuals ( $>1$ year old, excluding cubs) in all resident lion groups in our focal study area $\left(250 \mathrm{~km}^{2}\right)$. We provide a total count of lions from the final year of our study in 2010 when we were confident that all resident groups and individuals had been identified. We restricted our analysis to lion groups for which we had data on movements when people lived on the east and west side of the river (four groups).

We tested for responses of five dependent variables (attributes of lion locations) that we hypothesized might change in relation to human movements (i.e. people living east or west of the river was the independent variable for all analyses). We pooled data from lion groups across the 3 years of our study due to a relatively small sample size that prevented us from testing for differences in responses by year or by lion group. For each test, we used either a generalized linear mixed model (GLMM) or a linear mixed effects model with a random intercept (Zuur et al., 2009), with each 'follow' of a lion group as the random effect in both cases. We used these mixed models because the attributes of locations for a particular group on a given evening (i.e. group follow) exhibited obvious positive spatial autocorrelation within a given follow. In other words, the habitat used by a lion group at one time is usually similar to the habitat used a short time later. Instead of using an approach that considered every location an independent observation (potentially pseudoreplicating) or discarding all locations except one per group follow (potentially discarding valid information), we simply incorporated autocorrelation in the model structure (Zuur et al., 2009). We used GLMMs with a binomially distributed response variable to examine (1) the proportion of lion locations in closed vs. open habitats and (2) the proportion of lion locations in the CA. Using linear mixed effects models, with a random effect on the intercept to account for autocorrelation among fixes within an observation period, we examined (3) the average distance between a lion group and the permanent river, (4) the average distance of lion groups to the nearest active human settlement, and (5) the average nighttime prey density for lion locations.

Prior to analysis, we examined potential correlations among our five dependent variables. The three continuous dependent variables were weakly correlated ( $r$-values ranged from -0.18 to $0.05)$ and the two categorical dependent variables were independent $\left(\chi^{2}=33.8, p<0.001\right)$. We also compared the mean value for each continuous dependent variable within levels of the two categorical dependent variables. Five of six comparisons indicated that the two variables were associated ( $p<0.03$ in five comparisons), except that prey density was similar in the CA and buffer area $\left(t_{854}=0.5, p=0.633\right)$. Thus, lion movements that alter the land use that they occupy are also likely to cause changes in distance to water or distance to occupied human settlements. For all analyses, we used Bonferroni adjustment for multiple comparisons to reduce the potential for Type I error (Ott and Longnecker, 2001).

\section{Results}

\subsection{Density}

We unambiguously identified 34 lions (22 F, $12 \mathrm{M}$, excluding cubs and individuals $<1$ year) in an area of $250 \mathrm{~km}^{2}$, providing a density of 0.136 individuals $/ \mathrm{km}^{2}$. Though this density pertains to a relatively small area, it is comparable to or higher than many lion populations in well-known GPAs (Table 1). The 34 observed lions comprised 4 resident prides composed of 3-9 females ( mean $=5.5$, $\mathrm{sd}=3.0$ ), and 4 male coalitions of $1-2$ individuals. One pride contained 3 sub-adult males. With the exception of a coalition of 3 males that moved into the area in 2010 from an unknown source population, all male coalitions were clearly associated with 1-2 prides by the conclusion of our study. Though we did not include individuals $<1$ year in our total count, all resident lion prides had $\geqslant 1$ cub (<1 year) in 2010 .

\subsection{Space use patterns}

We recorded a total of 2084 GPS locations across the 4 focal groups that met criteria for inclusion in our analyses (see Methods). Of these, we recorded 1987 locations at night across 233 group follows and 97 daytime resting locations. However, we removed duplicate entries of GPS locations that did not provide new spatial information, such as when a group was resting or transitioning from resting to moving. This reduced dataset consisted of 1107 unique nighttime GPS locations across 233 lion group follows and 59 unique daytime resting locations.

Results from GLMMs (land use, habitat) and linear mixed models (distance to water, distance to settlements, prey density) indicated that the attributes of lion locations nested within a group follow were almost completely autocorrelated, and thus, each follow was considered the sampling unit. Recording multiple locations within a group follow did not provide any additional explanatory power in this analysis (though it might in other circumstances).

The probability of lions being in the CA was five times higher when people were settled on the west side of the river $(0.89,95 \%$ $\mathrm{CI}=0.70-0.96)$ compared to periods with people on the east side of the river $\left(0.17,95 \% \mathrm{CI}=0.08-0.32, t_{207}=5.92, p<0.001\right)$ (Figs. 1 and 2a). This result supports the hypothesis that lions utilized the CA to avoid close interaction with occupied human settlements. The probability of lions occurring in closed habitats (i.e. dense cover) increased by $44 \%$ when people were on the west side of the river $(0.85,95 \% \mathrm{CI}=0.72-0.93)$ compared to periods with people on the east side of the river $(0.59,95 \% \mathrm{CI}=0.46-0.72$, $t_{231}=3.28, p=0.001$ ) (Fig. 2b).

The mean distance of lions from the permanent river increased by $72 \%$, from $1735.7 \pm 132.9 \mathrm{~m}$, when people were living on the east side of the river to $2998.7 \pm 190.9 \mathrm{~m}$ when people lived on the west $\left(t_{231}=6.62, p<0.001\right)$ (Fig. $\left.3 c\right)$. This shift is related to increased lion use of the CA when people inhabited the west side of the river because the $C A$ is farther from the permanent river (Fig. 1). Although lions moved away from people, they did not fully compensate for shifts in human settlement. Lions were found at an average distance of $4779.0 \pm 151.8 \mathrm{~m}$ from occupied settlements when people lived on the east side of the river. This distance decreased to $3046.7 \mathrm{~m} \pm 218.1 \mathrm{~m}$ when people moved to the west 
Table 1

Lion population density estimates in Olkiramatian and Shompole Group Ranches relative to Government Protected Areas in Kenya and important lion populations elsewhere in Africa.

\begin{tabular}{lcll}
\hline Location & Study area $\left(\mathrm{km}^{2}\right)$ & Lion density (individuals/km ${ }^{2}$ ) & Reference(s) \\
\hline Ngorongoro Conservation Area (Tanzania) & 250 & $0.21-0.40$ & Hanby and Bygott (1995) and Packer et al. (2011) \\
Maasai Mara National Reserve (Kenya) & 1530 & $0.176-0.352$ & Ogutu and Dublin (2002) \\
Selous Game Reserve (Tanzania) & 1000 & $0.13-0.16$ & Creel and Creel (1997) and Spong (2002) \\
Serengeti National Park (Tanzania) & 2700 & $0.110-0.180$ & Mosser et al. (2009) and Packer et al. (2011) \\
Olkiramatian/Shompole Group Ranches (Kenya) & 250 & 0.136 & Schuette et al. (this study) \\
Kruger National Park (South Africa) & 4280 & 0.100 & Mills and Gorman (1997) \\
Koyiaki Group Ranch (Kenya) & 1120 & 0.046 & Ogutu et al. (2005) \\
Tsavo National Park (Kenya) & 690 & 0.040 & Patterson et al. (2004) \\
Hwange National Park (Zimbabwe) & 5884 & 0.027 & Loveridge et al. (2007) \\
\hline
\end{tabular}
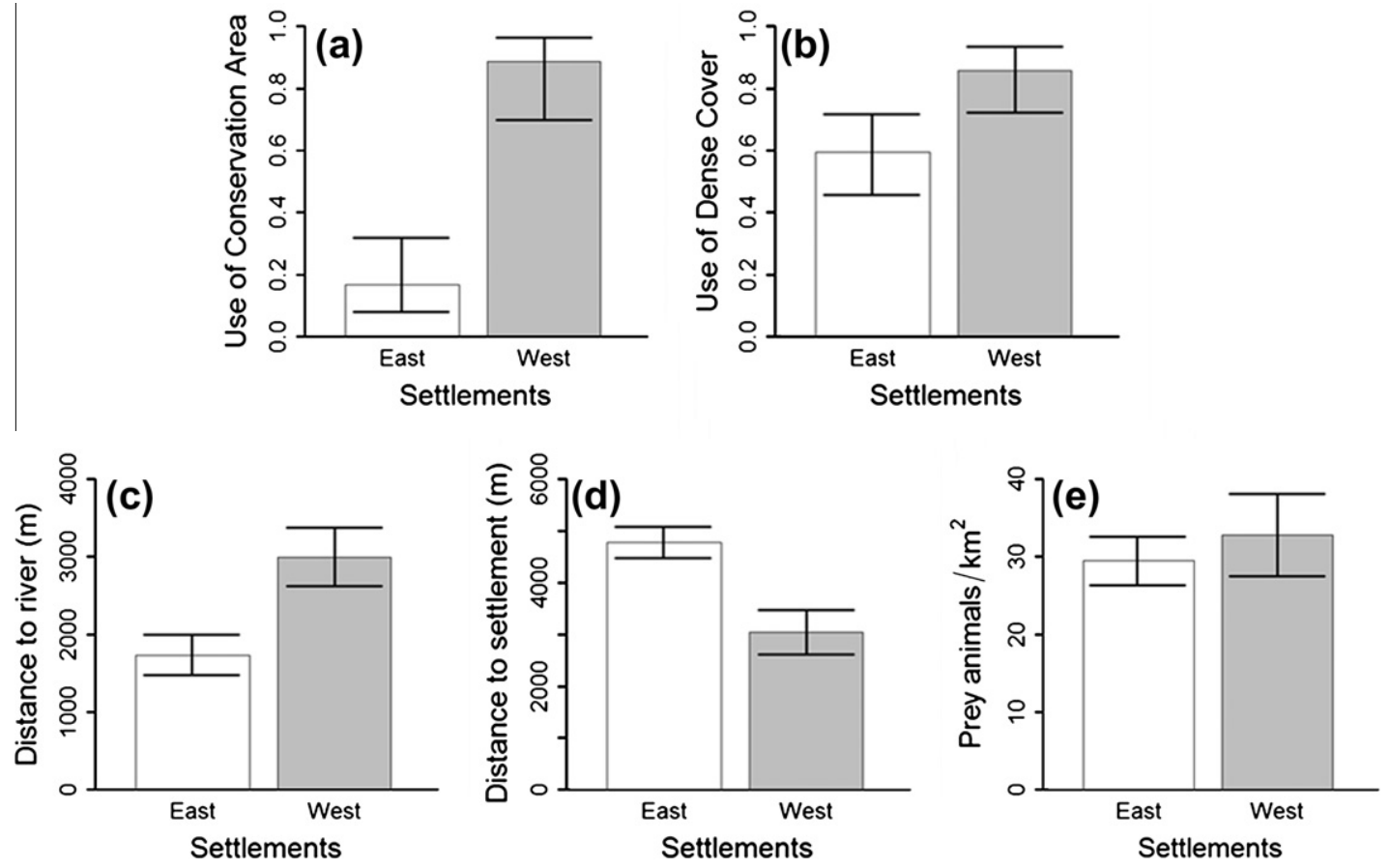

Fig. 2. Changes in the attributes of lion locations in a comparison of periods with people settled east or west of the permanent river. The probability of lion occurrence (use) and $95 \% \mathrm{CI}$ in (a) the Conservation Area and (b) dense cover when people were settled east or west of the permanent river. The average distance and 95\% $\mathrm{Cl}$ in meters to (c) the permanent river and (d) the nearest occupied human settlement when people were settled east or west of the permanent river. (e) The average prey density for lion locations and $95 \% \mathrm{CI}$ when people were settled east or west of the permanent river.

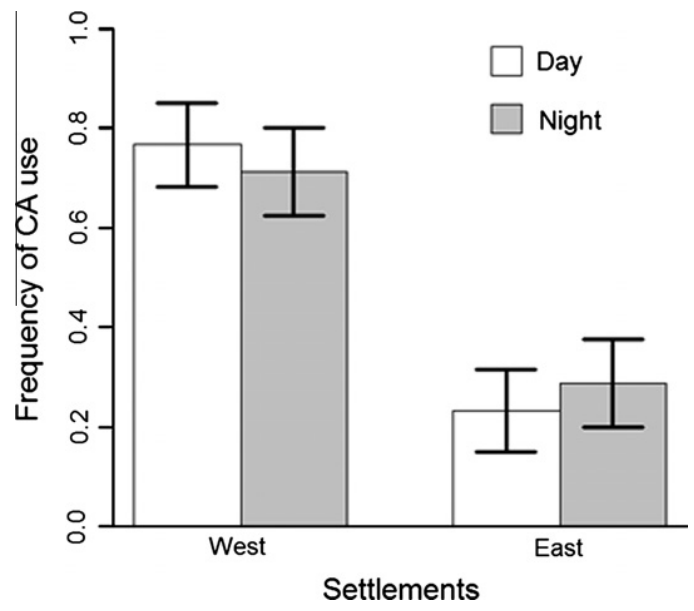

Fig. 3. The proportion of lion daytime resting locations and nighttime locations that occurred in the Conservation Area when the Maasai community was settled east or west of the permanent river. side of the river $\left(t_{231}=-7.94, p<0.001\right)$ (Fig. 2d). Lastly, lions used areas with similar prey density when people were on the east and west side of the river $\left(t_{132}=1.21, p=0.230\right)$. The average prey density when people were on the east was $29.5 \pm 1.6$ prey animals $/ \mathrm{km}^{2}$ and $32.9 \pm 2.7$ prey animals $/ \mathrm{km}^{2}$ when people were on the west (Fig. 2e).

Lion preference for the CA when people were settled on the west side of the river was similar for night locations and daytime resting locations $\left(\chi^{2}=0.65, p=0.420\right)$ (Fig. 3 ). This result indicates that lions took refuge in the CA both day and night when people inhabited the west side of the river, even though people were active only during the day.

\subsection{Carnivore conflict}

Spotted hyenas were the most common livestock predator ( $n=38$ [54\%] of 71 total incidents collected from 2008 to 2010), followed by leopard $(28 \%, n=20)$, lion $(10 \%, n=7)$, cheetah $(4 \%, n=3)$, and wild $\operatorname{dog}(4 \%, n=3)$. Despite these issues, to our knowledge, no large carnivores were killed locally during the course of this study by local residents or by the Kenya Wildlife Service. 


\section{Discussion}

The Olkiramatian and Shompole Group Ranches support a lion density of 0.136 individuals $/ \mathrm{km}^{2}$ (34 lions $/ 250 \mathrm{~km}^{2}$ ) a density figure that is comparable to GPAs such as Serengeti National Park (Table 1). This is an unexpected result given that this lion population occurs in a landscape situated relatively far from any GPA that also supports a dense population of livestock (Schuette, 2012). At the landscape level, high prey availability, seasonal human land use, and livestock husbandry practices that include herdsmen that oversee herds during the day and corral livestock at night, likely contribute to low rates of conflict and limit the need for lethal control of lions and other apex carnivores. These conditions distinguish Olkiramatian and Shompole from other East African rangelands that have been subdivided and converted to farms (Homewood et al., 2009). This shift in land use policy has increased the scope for conflict between lions and other apex carnivores with pastoralist and agro-pastoralist communities. These conflicts have led to subsequent reductions or elimination of local lion populations across several of these altered landscapes (Hazzah et al., 2009; Ogutu et al., 2005; Patterson et al., 2004).

Fundamentally, high apex carnivore density and low rates of conflict across an area that contains abundant livestock is increasingly rare, particularly in East African rangelands. Our data, though limited in scale, indicated that lions exhibited spatial variation in their use of the CA and dense cover in relation to movements of people and livestock. These patterns were observed during the day and night, which suggests that lions were shifting their movement patterns at a seasonal rather than diurnal level. Overall, a pattern that indicated lions shifted their spatial patterns in relation to movements of people and livestock is a unique result in East African rangelands. We anticipate these results will provide insight into patterns that might promote human-carnivore coexistence across similar landscapes where land subdivision and conversion to farmland is being considered.

Lions' increased use of dense cover in response to humans follows a pattern that has been observed in other apex carnivores. For example, a spotted hyena clan increased their use of dense shrublands when livestock densities increased along the border of the Maasai Mara National Reserve (Boydston et al., 2003). Increased use of dense cover by lions supports anecdotal inferences from other carnivore studies in human-modified landscapes (Funston, personal communication), suggesting that lions exposed to anthropogenic pressures are cryptic and nocturnal compared to GPA populations. In comparison to populations in GPAs, lions on this study site are extremely difficult to locate or observe without radiotelemetry, even though the population density is high and observation conditions are good. In sum, the availability of dense cover is likely an important feature of this landscape that provides a refuge from potential encounters with people and livestock. On a broader scale, the existence of a local Conservation Area likely reduced conflict in the same manner.

The average distance between lions and active human settlements declined 36\% when people moved to the west side of the river. Despite a clear shift in their distribution (Fig. 1), lions lived in substantially closer proximity to people when people settled west of the river. It is possible that lions could not move far enough to maintain constant separation from people without experiencing offsetting costs (e.g. increased distance to water, reduced prey density). It is also possible lions simply did not range near people when people were settled on the east because prey availability was lower there compared to the west side of the river. Thus, lions had little incentive to move to the east of the river. It is also possible that resident lions on the east side of the river prevented focal lion groups from moving across the river. Though this is possible because we did not monitor individual lion groups on the east side of the river, we consider this explanation unlikely due to overall low lion occupancy in this area (Schuette et al., in press). Regardless of the reason, people and lions came into closer contact when humans settled on the west of the river, which had the potential to increase encounters and conflicts. However, no increase in humancarnivore conflict was reported and no lions were killed due to conflict. Mobility across an open landscape allowed lions to shift their activity into the CA and densely vegetated areas to avoid people and livestock when they were in close proximity.

The average distance of lions to the permanent river nearly doubled $(1.7 \times)$ when people moved to the west side of the river during the dry season months. This result can be explained at least in part due to increased use of the $\mathrm{CA}$, which is relatively far from the river. However, the observed pattern is atypical for lions because they (like many stalking predators) are typically attracted to riparian areas near permanent rivers and water sources, particularly during the dry season (Mosser et al., 2009; Spong, 2002). Lion attraction to riparian habitat may also be affected directly by access to water itself, although lions are capable of surviving on the water provided by their prey (Schaller, 1972). Though lions and their ungulate prey have access to small springs flowing down from the Rift Valley escarpment into the CA and the dense woodlands supported by these springs, it is possible that displacement from areas near the permanent river was a cost of avoiding humans and livestock. Despite this spatial shift, woodlands in the CA provided a dry season foraging refuge for non-migratory populations of zebra and wildebeest, impala, Cape buffalo, and lesser kudu, which lions preyed upon during the dry season (Schuette, unpublished data). Thus it is possible that lions were actually attracted to the CA because of dry season prey availability, rather than a retreat from human settlements. Regardless of the causal mechanisms, we observed similar prey densities at lion locations when people inhabited the east and west sides of the river, demonstrating that lions were still able to maintain both adequate separation from people and adequate access to prey (Hopcraft et al., 2005).

Though our focal study area was relatively small $\left(250 \mathrm{~km}^{2}\right)$, the Olkiramatian and Shompole area is linked with a larger landscape $\left(>8000 \mathrm{~km}^{2}\right)$ that includes several GPAs, including the Maasai Mara National Reserve and Amboseli National Park in Kenya, and may extend to Lake Manyara and Tarangire National Parks in Tanzania. To date, very little quantitative data exists for much of this trans-boundary region, particularly for extensive mixed-use rangelands that are undergoing or are threatened by land use changes (Homewood et al., 2009). We do not know whether the Olkiramatian and Shompole lion population is representative of the entire region, or whether we happened to observe a locally high density population across a landscape with low overall lion densities. Future research should investigate to what extent this population is representative of the area, to what extent it is linked to other lion populations in regional GPAs and other mixed-use rangelands (Pusey and Packer, 1987), and test the generality of our inferences about the factors that promoted high lion density and low conflict with humans on this site.

\section{Conclusions}

In recent decades, quantitative evidence and public opinion suggest that conflict-prone carnivores may be incompatible with most current livestock production practices. However, we found that an apex carnivore cannot only persist alongside people and livestock, but that this apex carnivore, its common native prey, and livestock all co-occurred at relatively high densities. Identifying generalizable attributes of this landscape and local human land 
uses that have allowed this to occur, can at a minimum provide a starting point to address carnivore conservation and management outside of GPAs, for which little or no data currently exists, particularly for species that occur in regions where livestock production is a predominant land use strategy.

We propose five landscape features and human land uses practices observed in Olkiramatian and Shompole that should be evaluated in other systems. First, an unfenced landscape may promote co-occurrence of apex carnivores with people and livestock. An open landscape may allow people, livestock, native ungulates, and carnivores the ability to make spatial adjustments in response to seasonal weather patterns, environmental change, ecological processes, and anthropogenic pressures, and thus avoid conflict. Second, heterogeneity in habitats and land use provides critical refuges from competitive pressures for ungulate prey and potentially dangerous interactions for large carnivores. Third, seasonal variation in livestock grazing practices across a set of land uses may promote co-occurrence of livestock and native ungulate populations. These conditions may provide sufficient native prey for apex carnivores to avoid preying upon livestock. Fourth, corralling livestock in secure structures at night may reduce carnivore conflict. People and livestock are absent from the Olkiramatian and Shompole landscape for 12 out of every $24 \mathrm{~h}$ cycle, which reduces the potential for nighttime attacks on livestock and may reduce interference competition between livestock and native ungulate prey populations. Fifth, a relatively small Conservation Area set aside for conservation purposes and livestock grazing during extreme drought may facilitate co-occurrence of people and apex carnivores. Designating these Conservation Areas may provide important habitat for wildlife that may also benefit ranching communities by providing a buffer between conflict-prone carnivores and their livestock, and providing a 'grass bank' that can be accessed during drought conditions. None of these conclusions should be unique to lions, and we suggest that they might guide general policies to conserve large carnivores outside of GPAs.

\section{Acknowledgements}

We thank the Kenya Ministry of Science and Technology, the Kenya Wildlife Service, and the South Rift community for permission to conduct our research. All animal handling procedures were approved by the Institutional Animal Care and Use Committee at Montana State University and the Kenya Wildlife Service. We thank J. Kamanga, S. Russell, and D. Western for their coordination efforts, and E. Christianson, M. Kapoli, A. Kuseyo, A. Matole, P. Moikinyo, L. Mpukere, J. Njonjo, P. Oltubulai, C. Schuette, and the Maasai Resource Assessors for their assistance in the field. This research was funded by the National Science Foundation, the Cincinnati Zoo, and Panthera.

\section{References}

Bauer, H., Nowell, K., Packer, C., 2008. The IUCN Red List of Threatened Species: Lion (Panthera leo). IUCN. <http://www.iucnredlist.org/apps/redlist/details/15951/ $0>$.

Becker, M., Watson, F., Droge, E., Leigh, K., Carlson, R., Carlson, A., in press. Estimating male loss from edge effects in three Zambian lion populations. J. Wildlife Manage.

Boydston, E.E., Kapheim, K.M., Watts, H.E., Szykman, M., Holekamp, K.E., 2003. Altered behaviour in spotted hyenas associated with increased human activity. Anim. Conserv. 6, 207-219.

Buckland, S.T., 2001. Introduction to Distance Sampling: Estimating Abundance of Biological Populations. Oxford University Press, Oxford.
Chandler, R.B., 2012. Distance Sampling Analysis in Unmarked. USGS, USGS Patuxent Wildlife Research Center.

Chardonnet, P., 2002. Conservation of the African Lion: Contribution to a Status Survey. International Foundation for the Conservation of Wildlife, France \& Conservation Force, USA.

Craigie, I.D., Baillie, J.E.M., Balmford, A., Carbone, C., Collen, B., Green, R.E., Hutton, J.M., 2010. Large mammal population declines in Africa's protected areas. Biol. Conserv. 143, 2221-2228.

Creel, S., Creel, N.M., 1997. Lion density and population structure in the Selous Game Reserve: evaluation of hunting quotas and offtake. Afr. J. Ecol. 35, 83-93.

Estes, J.A., Terborgh, J., Brashares, J.S., Power, M.E., Berger, J., Bond, W.J., Carpenter, S.R., Essington, T.E., Holt, R.D., Jackson, J.B.C., Marquis, R.J., Oksanen, L., Oksanen, T., Paine, R.T., Pikitch, E.K., Ripple, W.J., Sandin, S.A., Scheffer, M., Schoener, T.W., Shurin, J.B., Sinclair, Anthony R.E., Soulé, M.E., Virtanen, R., Wardle, D.A., 2011 Trophic downgrading of planet Earth. Science 333, 301-306.

Gittleman, J.L., Funk, S.M., Macdonald, D.W., Wayne, R.K. (Eds.), 2001. Carnivore Conservation. Cambridge University Press, Cambridge, UK.

Groom, R., Harris, S., 2010. Factors affecting the distribution patterns of zebra and wildebeest in a resource-stressed environment. Afr. J. Ecol. 48, 159-168.

Hanby, J.P., Bygott, J.D., 1995. Population changes in lions and other predators. In: Sinclair, A.R.E., Norton-Griffiths, M. (Eds.), Serengeti: Dynamics of an Ecosystem. University of Chicago Press, p. 249.

Hazzah, L., Borgerhoff Mulder, M., Frank, L.G., 2009. Lions and Warriors: socia factors underlying declining African lion populations and the effect of incentive-based management in Kenya. Biol. Conserv. 142, 2428-2437.

Homewood, K., Kristjanson, P., Trench, P.C., 2009. Changing land use, livelihoods, and wildlife conservation in Maasailand. In: Staying Maasai? Livelihoods, Conservation and Development in East African Rangelands. Springer Science + Business Media, New York, pp. 1-42.

Hopcraft, G., Sinclair, A.R.E., Packer, C., 2005. Planning for success: Serengeti lions seek prey accessibility rather than abundance. J. Anim. Ecol. 74, 559-566.

Kenya's National Large Carnivore Task Force, 2010. Conservation and Management Strategy for Lions and Spotted Hyenas in Kenya, 2009-2014. Kenya Wildlife Service, Nairobi, Kenya, p. 52.

Loveridge, A.J., Searle, A.W., Murindagomo, F., Macdonald, D.W., 2007. The impact of sport-hunting on the population dynamics of an African lion population in a protected area. Biol. Conserv. 134, 548-558.

Marshall, F., 1990. Origins of specialized pastoral production in East Africa. Am. Anthropol. 92, 873-894.

Mills, M.G.L., Gorman, M.L., 1997. Factors affecting the density and distribution of wild dogs in the Kruger National Park. Conserv. Biol. 11, 1397-1406.

Mosser, A., Fryxell, J.M., Eberly, L., Packer, C., 2009. Serengeti real estate: density vs. fitness-based indicators of lion habitat quality. Ecol. Lett. 12, 1050-1060.

Ogutu, J.O., Dublin, H.T., 2002. Demography of lions in relation to prey and habitat in the Maasai Mara National Reserve, Kenya. Afr. J. Ecol. 40, 120-129.

Ogutu, J.O., Bhola, N., Reid, R., 2005. The effects of pastoralism and protection on the density and distribution of carnivores and their prey in the Mara ecosystem of Kenya. J. Zool. 265, 281-293.

Ott, R.L., Longnecker, M., 2001. An Introduction to Statistical Methods and Data Analysis, fifth ed. Duxbury, Pacific Grove, California.

Packer, C., Brink, H., Kissui, B.M., Maliti, H., Kushnir, H., Caro, T.M., 2011. Effects of trophy hunting on lion and leopard populations in Tanzania. Conserv. Biol. 25 142-153.

Patterson, B.D., Kasiki, S.M., Selempo, D., Kays, R.W., 2004. Livestock predation by lions (Panthera leo) and other carnivores on ranches neighboring Tsavo National Parks, Kenya. Biol. Conserv. 119, 507-516.

Pennycuick, C.J., Rudnai, J., 1970. A method of identifying individual lions Panthera leo with an analysis of the reliability of identification. J. Zool. 160, 497-508.

Pusey, A.E., Packer, C., 1987. The evolution of sex-biased dispersal in lions. Behavior $101,275-310$

Schaller, G.B., 1972. The Serengeti Lion: a Study of Predator-Prey relations University of Chicago Press.

Schuette, P., 2012. Factors Affecting the Distribution and Abundance of Carnivores and their Ungulate Prey Across a Communally Owned Rangeland in Kenya. Ph.D. Dissertation, Montana State University, Bozeman, Montana.

Schuette, P., Wagner, A.P., Wagner, M.E., Creel, S., in press. Occupancy patterns and niche partitioning within a diverse carnivore community exposed to anthropogenic pressures. Biol. Conserv.

Spong, G., 2002. Space use in lions, Panthera leo, in the Selous Game Reserve: social and ecological factors. Behav. Ecol. Sociobiol. 52, 303-307.

Tarayia, G.N., 2004. Legal perspectives of the Maasai culture, customs, and traditions. Ariz. J. Int. Comp. Law 21, 183.

West, G., Heard, D.J., Caulkett, N., 2007. Zoo Animal and Wildlife Immobilization and Anesthesia. Blackwell Publishing, Ames, Iowa.

Woodroffe, R., 2000. Predators and people: using human densities to interpret declines of large carnivores. Anim. Conserv. 3, 165-173.

Woodroffe, R., Ginsberg, J.R., 1998. Edge effects and the extinction of populations inside protected areas. Science 280, 2126-2128.

Zuur, A.F., Ieno, E.N., Walker, N.J., Saveliev, A.A., Smith, G.M., 2009. Mixed Effects Models and Extensions in Ecology with R. SpringerLink, New York. 